\section{The effect of atropine and methyl atropine on the heart rate of rats'}

\section{T. L. HOLDSTOCK and H. B. INGLE, University of the Witwatersrand, Johannes- burg, South Africa}

Three experiments, designed to determine the effects of different doses of atropine sulphate and MeA on the HR of rats, were carried out. The amount of acceleration elicited by the drugs was relatively small. This was attributed to the high baseline $H R$ that resulted from conditions, small doses of MeA resulted in large increases in $H R$.

A considerable amount of information is available concerning the effects of atropine on cerebral electrical activity and behavior of animals (Carlton, 1963; Longo, 1966). However, much less work has been done on the effects of this alkaloid on the autonomic nervous system of animals, especially of white rats. Considerable increase in heart rate (HR) has been reported following administration of atropine in dogs (Lauener \& Bovet, 1952; Marshall, 1926) and cats (Moore \& Cannon, 1930). However, the one study which presented some data on the effect of atropine sulphate on the HR of white rats, reported deceleration, rather than acceleration, of $\mathrm{HR}$ in two of three animals studied (Covian, Lico, \& Rodriques, 1966). Since we wanted to use atropine to prevent effects of brain stimulation upon cholinergic activity in the cardiac system, it seemed desirable to investigate a number of parameters relevant to the action of the drug. Besides the importance of dose level, time of onset and duration, we were also interested in comparing the effects of atropine sulphate and methyl atropine nitrate (MeA).

\section{SUBJECTS}

Adult male hooded rats of the LongEvans strain were used. During the first two experiments they were maintained six per cage, but during the third experiment they were housed individually. Except for a few animals in Experiment 3, the Ss were all experimentally naive.

\section{DRUGS}

Solutions of atropine sulphate were prepared at concentrations of 1.0,5.0 and $50 \mathrm{mg} / \mathrm{kg}$ and of $\mathrm{MeA}^{2}$ at concentrations of consisted of normal saline. All injections were intraperitoneal (at a constant volume of $1 \mathrm{cc} / \mathrm{kg}$ ) and were given at the beginning of each session. restraining the animals. Under freely moving $0.1,1.0$ and $5.0 \mathrm{mg} / \mathrm{kg}$. Control injections

\section{APPARATUS}

A Beckman Type $R$ dynograph was used to obtain records of HR. In the first two experiments the animals were restrained and HR was recorded from No. 26-gauge stainless-steel wires looped through the skin (Holdstock \& Schwartzbaum, 1965). The electrode assembly used in the third experiment consisted of No. 26-gauge stainless-steel wires, about 12 and $6 \mathrm{~cm}$ long, respectively, soldered to Amphenol connecting pins. The wires were insulated by threading, all except the last $1 \mathrm{~cm}$, through flexible nylon tubing (Portex Size 00). The free piece of wire was bent into a loop and fed back into the tubing.

The electrode assembly was implanted under pentothal anesthesia. After shaving the head, as well as small regions in the sacral midline and left thoracic region, the animal was placed in a stereotaxic headholder. The scalp was exposed and small incisions made in the other shaved areas. A blunt surgical probe was attached to the wire loop of the electrode and fed beneath the skin to pass out through the incision, drawing the plastic-sheathed electrode along its track. The shorter of the electrode assemblies was bent along the side of the body to lie ventral to the thoracic cavity. The looped ends of the electrodes were stitched to the inner membranes and the wound closed. The pins were fixed to the skull with dental cement and anchoring screws. By connecting the electrode assembly to a two-channel commutator, recordings of HR, relatively free from movement artifact, could be obtained.

During the first two experiments HR measurements were obtained while the restrained animals were placed in a Grason-Stadler sound-attenuating chamber. During Experiment 1, this chamber was in the same room as the recording equipment. In an attempt to mask out unwanted sounds, white noise was fed into the chamber and the room. This was not done in Experiment 2, when the sound-attenuating chamber was located in an adjacent room. During Experiment 3, tests were also carried out in the room adjacent to the one with the recording equipment, using cages similar to the ones the animals were housed in.

\section{EXPERIMENTAL PROCEDURE}

In all three experiments, an initial adaptation session preceded actual testing. In the first two experiments, the animals were restrained for a 2 -h period following a pseudo-intraperitoneal injection. Two animals were tested simultaneously in separate cages during this phase.

In each experiment, adaptation was followed by three experimental sessions, at least 3 days apart. One session constituted a control injection of normal saline, while drugs and dose level were manipulated on the other two. The presentation of treatments followed a 3 by 3 Latin square

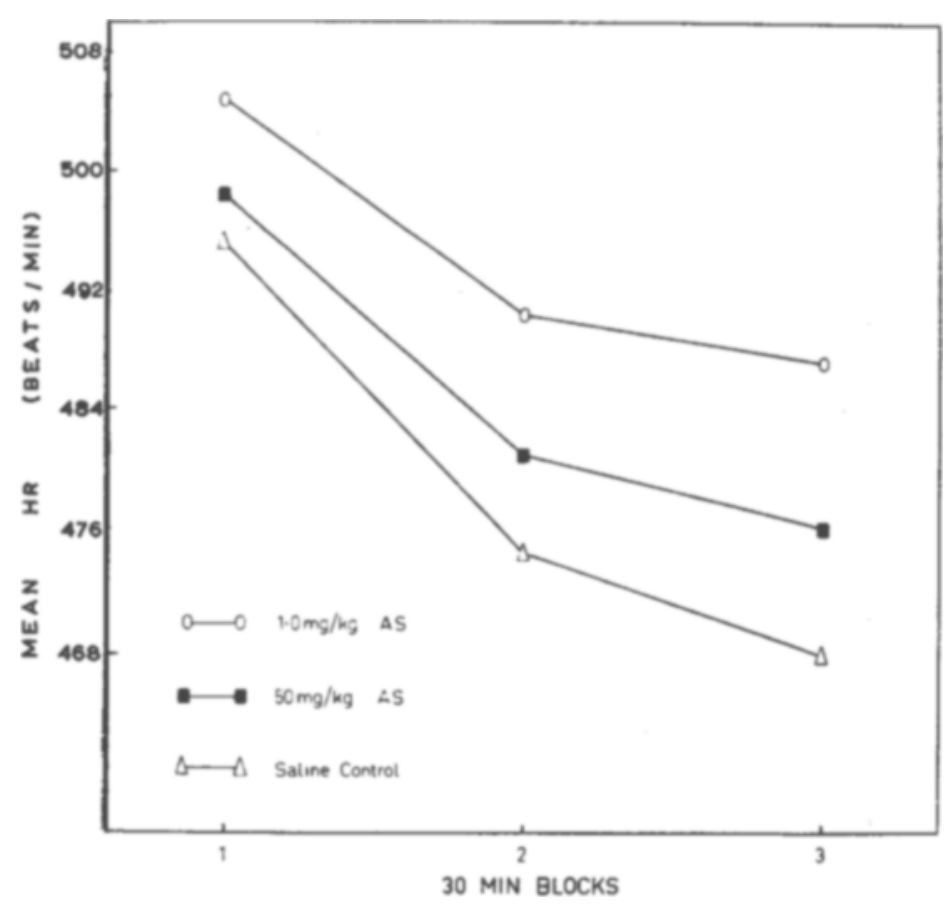

Fig. 1. Mean HR during successive blocks of $30 \mathrm{~min}$ (AS-atropine sulphate). 


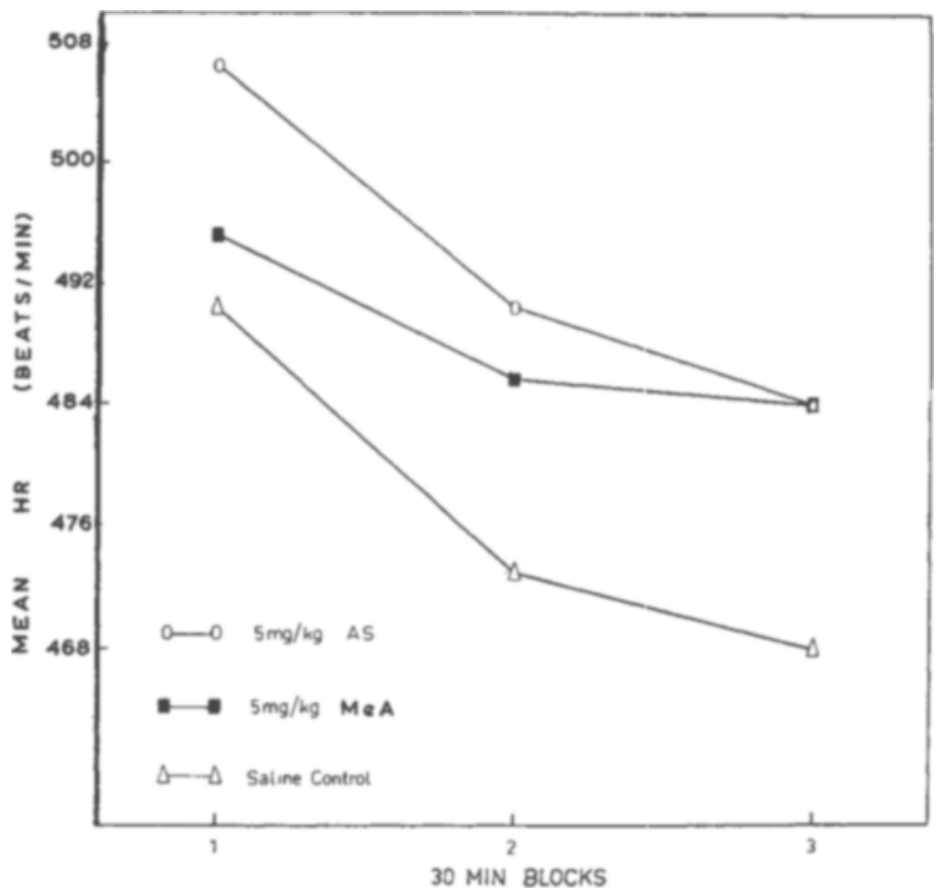

design, which was replicated six times in the first two experiments and four times in the last. This approach allowed each animal to serve as his own control. It also controlled for the order in which the drugs were administered, so that each treatment occurred an equal number of times in each of the three sessions.

Each session lasted $90 \mathrm{~min}$ in the first two experiments, and $180 \mathrm{~min}$ in the third. HR was recorded every $10 \mathrm{~min}$ from the time of injection in Experiments 1 and 2, and every 20 min in Experiment 3.

\section{HR SCORING}

The mean HR was determined for a $2-\mathrm{sec}$ period preceded by at least $5 \mathrm{sec}$ of artifact-free recording. In these measurements the distance to the nearest $0.5 \mathrm{~mm}$ occupied by the number of beats most closely approximating the 2 -sec period $(50 \mathrm{~mm})$ was first determined. This value was then divided by the number of intervals

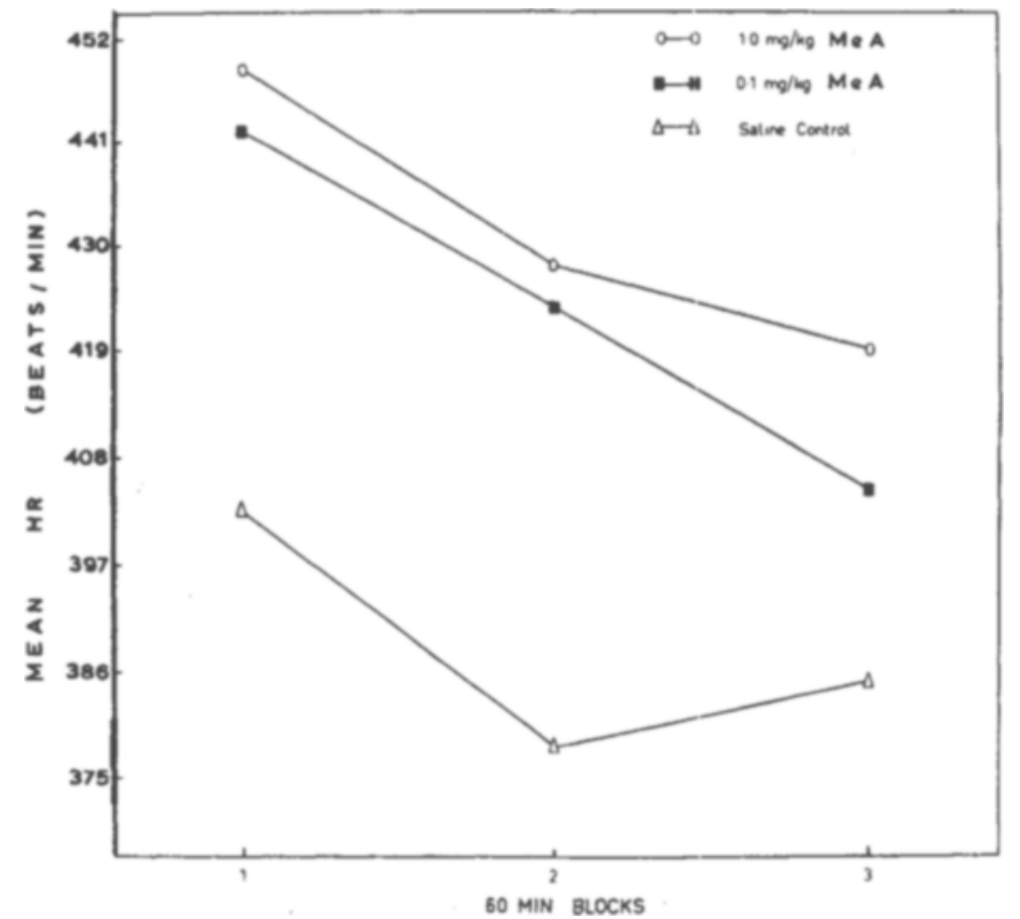

Fig. 2. Mean HR during successive blocks of $30 \mathrm{~min}$.

between beats to yield a mean IBI for each $2-\sec$ period; these values, expressed in millimeters, can be translated into rate by dividing into the fixed paper speed of $25 \mathrm{~mm} / \mathrm{sec}$. The mean interbeat interval was averaged over $30-\mathrm{min}$ periods in the first two experiments, and over $60 \mathrm{~min}$ in the last. RESULTS

Experiment 1

Eighteen animals were used to compare the effects of normal saline, 1.0 and $50.0 \mathrm{mg} / \mathrm{kg}$ atropine sulphate on HR.

Overall, the HR averaged 479 beats $/ \mathrm{min}$ during the control condition, 495 beats/min during the $1.0 \mathrm{mg} / \mathrm{kg}$ condition, and 485 beats $/ \mathrm{min}$ during $50.0 \mathrm{mg} / \mathrm{kg}$. Although the amount of acceleration caused by the drugs was not great, the treatment effect was significant at the .01 level $(F=5.32$, $\mathrm{df}=2 / 135$ ). Further analyses, made by Duncan's Multiple Range Test, revealed that only the $1.0-\mathrm{mg} / \mathrm{kg}$ and saline conditions differed significantly. From Fig. 1 it can be seen that the effect of the drug was already apparent after $30 \mathrm{~min}$, and that it lasted for the duration of the session, despite a tendency for the HR to decelerate during the session Period main effect: $F=10.65$, $\mathrm{df}=2 / 135, \mathrm{p}<.001)$.

\section{Experiment 2}

Eighteen new animals were used to compare the effects of saline, $5.0 \mathrm{mg} / \mathrm{kg}$ atropine sulphate and $5.0 \mathrm{mg} / \mathrm{kg} \mathrm{MeA}$ on $H R$. In light of the relatively small accelerative effect that was found in Experiment 1, inclusion of MeA seemed advisable on the basis of its potency as a peripheral anticholinergic agent (Bulbring \& Dawes, 1945; Graham \& Lazarus, 1940).

Overall, cardiac rates were similar to those of the first experiment. The averages were 477,489 , and 493 beats/min during the saline, MeA, and atropine sulphate conditions, respectively. Although relatively small, the treatment effect was statistically significant $(F=3.40, \mathrm{df}=2 / 135, \mathrm{p}<.05)$. A Duncan Multiple Range Test further showed that only the atropine sulphate and control conditions differed significantly. As before, this difference was evident within $30 \mathrm{~min}$ after injection and it was again superimposed upon a general slowing towards the end of the session $(F=4.42$, $\mathrm{df}=2 / 135, \mathrm{p}<.05)$.

$$
\text { Experiment } 3
$$

In both Experiments 1 and 2, atropine yielded increases in HR of little more than $3 \%$. Although these changes were statistically significant, they were, nonetheless, surprisingly small. In Experiment 3 the

Fig. 3. Mean HR during successive blocks of $60 \mathrm{~min}$. 
possibility was investigated that the restrained condition elevated baseline levels of HR to such an extent that it masked the accelerative effect of atropine. For this reason, 12 freely moving animals were used to determine the effect of 0.1 and $1.0 \mathrm{mg} / \mathrm{kg}$ MeA on HR. Normal saline again served as the control. A few of the animals had been used as Ss in Experiment 2, 4 weeks previously.

Compared to the first two experiments, approximately $10 \%$ change in $\mathrm{HR}$ was brought about by administration of the drug. Overall, averages of 422 and 431 beats/min were obtained during the 0.1 - and $1.0 \mathrm{mg} / \mathrm{kg}$ conditions, respectively, compared to 387 beats/min during the control condition. The effect of the drugs was verified statistically $(\mathrm{F}=15.71, \mathrm{df}=2 / 81$, $\mathrm{p}<.001$ ). The Duncan Multiple Range Test further showed that both drug conditions were significantly different from the control condition without differing from each other.

Figure 3 reveals that the effect of the drug lasted for the duration of the $180-\mathrm{min}$ session and that it was once more superimposed upon a general slowing of $H R$ towards the end of the session ( $F=8.60$, $\mathrm{df}=2 / 81, \mathrm{p}<.001)$. Finally, it was apparent that the absolute levels of HR were much less than during the restrained condition of the first two experiments.

\section{DISCUSSION}

The data indicate that acceleration of HR was elicited by both atropine sulphate and its quaternized derivative, MeA. It is also clear that "the law of initial values" must be considered in evaluation of the drug effects. Not only were larger increases in HR encountered under the freely moving condition, when overall HR was slower, but the inability of some dosage levels to cause a significant acceleration during the restrained condition, could most probably be explained by the higher baseline values. However, "the law of initial values" does not explain why such a large dose as $50.0 \mathrm{mg} / \mathrm{kg}$ atropine sulphate did not increase HR more than doses of 5.0 and $1.0 \mathrm{mg} / \mathrm{kg}$ atropine sulphate, unless it is argued that the high dose, superimposed upon an already high HR, initiated homeostatic control that prevented too high a rate. However, a more likely explanation is that this high atropine dose could block the release of adrenalin from the adrenal medulla, which is cholinergic, and that this block in turn abolished the effect of released adrenalin on the HR.

It was also of interest to note that $5.0 \mathrm{mg} / \mathrm{kg} \mathrm{MeA}$ was less effective in accelerating $H R$ than a comparable dose of atropine sulphate. Unfortunately, Experiment 3 was well in progress before analysis of the results of Experiment 2 was completed. It thus remains a matter for future research to compare the tertiary and quaternized derivatives of atropine under freely moving conditions when baseline values of $H R$ are lower. REFERENCES

BULBRING, E., \& DAWES, G. S. A method for the assay of atropine substitutes on the salivary secretion. Journal of Pharmacology \& Experimental Therapeutics, $1945,84,177-183$.

CARLTON, P. L. Cholinergic mechanisms in the control of behavior by the brain. Psychological Review, 1963, 70, 19-39.

COVIAN, M. R., LICO, M. C., \& RODRIGUES, J. $A$. Blood pressure and respiratory changes by stimulation of brain septal area in rats. Acta Physiologica Latino-Americana, 1966, 16 , 99-105.

GRAHAM, J. D., \& LAZARUS, S. The actions of methyl atropine nitrate (Eumydrin). Journal of Pharmacology \& Experimental Therapeutics, 1940,70,165-170.

HOLDSTOCK, T. L., \& SCHWARTZBAUM, J.S. Classical conditioning of heart rate and galvanic skin response in the rat. Psychophysiology, $1965,2,25-38$
LAUENER, H., \& BOVET, D. Mécanisme et modification pharmacodynamique de la tachycardie atropinique du chien éveillé. Helvetica Physiologica et Pharmacologica Acta, 1952, 10, 413-426.

LONGO, V. G. Behavioral and electroencephalographic effects of atropine and related compounds. Pharmacological Reviews, 1966 18,965-996.

MARSHALL, E. L. The influence of atropine and $\mathrm{CO}_{2}$ on the circulation of the unanesthetized dog. Joumal of Pharmacology \& Experimental Therapeutics, 1926, 29, 167-175.

MOORE, R. M., \& CANNON, W.B. The heart rate of unanesthetized, normal vagotomized, and sympathectomized cats as affected by atropine and ergotoxine. American Journal of Physiology, 1930, 94, 201-208.

\section{NOTES}

1. The investigation was supported by the South African Council for Social Research and by the American Psychological Foundation.

2. Methyl atropine nitrate was supplied by Winthrop Laboratories, Mobeni, Natal, and by Smith, Kline, and French Laboratories, Isando, Transvaal

\section{Behavioral thermoregulation at high environmental temperatures: The intra-session pattern of cooling and resting'}

DONALD A. KRISTT, Department of Anatomy, New York University Medical Center, New York, N.Y. 10016, and Department of Social Sciences, Polytechnic Institute of Brooklyn, N.Y., and JERI A. SECHZER, Departments of Rehabilitation Medicine and Anatomy, New York University Medical Center, New York, N.Y. 10016

Rats exposed to a hot environment are trained to cool themselves by pressing a lever for a blast of cold air. All Ss exhibit an intrasession pattern of behavior consisting of alternating periods of cooling and resting. Ss are trained in one of two cooling situations in an effort to examine whether this pattern represents an artifact or an actual thermoregulatory phenomenon.

In the course of investigating behavioral thermoregulation at high environmental temperatures (Kristt \& Sechzer, in press) we have noted, as have Epstein (1968) and Baldwin \& Ingram (1967), that within any particular test session a $S$ would exhibit a pattern of behavior comprised of periods of high activity alternating with periods of no activity. The experiments presented below were undertaken to determine if this pattern represented an artifact or an actual thermoregulatory phenomenon.
Our approach to this question was based on the assumption that the Ss periodically stopped bar pressing because they had temporarily satisfied a "thermal drive" by means of their cooling behavior. We expected, then, that if we could train Ss in a situation in which cooling was more effectively accomplished in a given period of time, then this "cooling-resting" pattern should become more conspicuous. The importance of such a phenomenon to our understanding of the whole thermoregulatory process-physiological as well as behavioral-will be considered.

\section{METHOD AND MATERIALS}

The Ss were six male naive SpragueDawley rats. They weighed from $320450 \mathrm{~g}$ and were housed in metal cages in which unrestricted food and water was available.

The ambient temperature was $24 \operatorname{deg} \pm 2 \operatorname{deg} C$.

The training and testing apparatus consisted of a modified Skinner box, placed within an environmental chamber, the temperature of which was stable to $\pm 2 \mathrm{deg} C{ }^{2}$ The reinforcement consisted of a burst of cold air ( $14 \mathrm{deg} \pm 1 \mathrm{deg} C$ ) directed onto the perforated front face of the Skinner box, above the lever.

The Ss were randomly divided into two groups of three each. Those Ss in the group 